\title{
The Pricing model for Transmission and Distribution Tariff Under Differ- ent Voltage Levels Based on the Long-run Marginal Cost Method
}

\author{
Yan Qing-you ${ }^{1}$, Sun Yi-xin ${ }^{1,2}$, Qin Chao ${ }^{1}$ and Tan Zhong-fu ${ }^{1}$ \\ ${ }^{1}$ Institute of Energy Economics and Environment, North China Electric Power University, Beijing, China \\ ${ }^{2}$ State Grid Energy Research Institute, Beijing, China
}

\begin{abstract}
An incremental load model during peak load period in which both load rate and simultaneity of load is given. To mitigate the influence of irregular putting into operation of transmission and distribution equipment on fluctuation of marginal cost of transmission and distribution, an annuity calculation method of average incremental cost is proposed, and a calculation model based on long-term marginal cost, which can rationally share the expense of voltage classes, is built. According to incremental load during peak load period and the final average incremental cost to be borne by different voltage classes, the transmission and distribution prices for different voltage classes are calculated. Case study on longterm marginal cost of a certain regional power network is carried out, and calculation results show that the proposed transmission and distribution pricing method can reflect economic trend in the future and is favorable to eliminate crosssubsidies as well as make the electricity prices borne by various consumers in different voltage classes more fair and reasonable.
\end{abstract}

Keywords: Transmission and distribution price, long-term marginal cost, average incremental cost, voltage classes, allocation.

\section{INTRODUCTION}

With the national economy smoothly and relatively rapid development, electrovalence reform had been one of the key factors in power industry reform and development; it is also an important tool that reflects power industry management thought and industry development direction. Applying science, reasonable, regulatory pricing methods to set electrovalence have the important theory value and practical significance for electrovalence must be given lull play in the allocation of power resources.

Methods of setting electrovalence fall into two main groups, accounting cost pricing method and marginal cost pricing method. Traditional embedded cost method includes postage stamp method [1-2], contract route method [3], line by line calculation method and MK km method [4-6] and so on. Literature [7-8] improved MK km method. Literature [7] researches reactive power based on comprehensive cost allocation in the electricity market of associated operation pattern based on power flow composition analysis, and proposes a kind of functional computational method. Literature [8] proposes a transmission service pricing method based on physical path capital flow tracking, relative to $\mathrm{MW} \mathrm{km}$ method, the method is known as capacity flow-capacity path method. Literature [9] considers system reliability and providing economy information method relatively. These methods have a common characteristic that focus on compensating the actual cost for Power Grid Corp [10]. At the same time, these methods have some shortcomings, such as postage stamp method crossing subsidy seriously, contract route method' routes uncertainly and loop network problem inextricability, line by line calculation method' results relating to calculation transport business order.

Different from accounting cost method setting electrovalence, long-term marginal cost method based mainly on incremental situation of the generation and grid investment and incremental situation of load power capacity to calculate marginal cost in the future planning period, and then form all kinds of electrovalence. It reflects future economic cost changing trend and future resources value; therefore, it can bring about real economic signal for users.

Electric power system long-term marginal costs always include long-term generation marginal cost $[11,12]$ and long-term transmission and distribution marginal cost. Longterm transmission and distribution marginal cost is the increase of the transmission and distribution expenses for meeting users' future unit load demand growth. As a result of transmission and distribution equipment its own characteristics, relative to electricity load uniform growth, transmission and distribution equipment investment exists superior non uniformity, especially is higher voltage level, construction and operation of equipment to achieve the rated operating conditions after a few years later. Therefore, comparing with load increasing situation, its investment volatility is great. In order to gentle the impact of putting into the kind of equipment' non uniformity for transmission and distribution marginal cost fluctuation, the paper adopts long-term average incremental cost method [13] to calculate transmission and distribution long-term marginal cost, each voltage 
classes peak load incremental, expense incremental and average incremental cost and annuity in the planning period.

\section{PEAK INCREMENTAL LOAD CALCULATING METHOD AND MODEL}

\subsection{Peak Load Calculating in the Planning Period}

As a result of long-term marginal cost pricing method considering the impact of increasing of future load for the increasing of electric power system cost, therefore, electric power system load forecast is the foundation of calculating electric power system long-term marginal cost.

In order to calculate each voltage classes' incremental load in the system peak period, we need to forecast all kinds of load electricity consumption yearly of each voltage classes, then according to all kinds of users load rate, calculating each users' highest power consumption load of corresponding yearly maximum load day. Because each user's load characteristic is different, the highest load occurrence time and load rate are different, the impact for system highest load is different. In order to describe the impact of each user highest load for system highest load, after considering each load simultaneity factor, we need calculate each voltage classes load of system peak load period.

Assuming the planning period is $n$ year; $t=1,2, \mathrm{~L}, n$ the voltage class from high to low are $500 \mathrm{kV}, 220 \mathrm{kV}, 110 \mathrm{kV}$, $35 \mathrm{kV}, 10 \mathrm{kV}, 380 / 220 \mathrm{~V}, k=1,2, \mathrm{~L}, 6$; each voltage class user type is $p, p=1,2, \mathrm{~L}, P$. Assuming user $p$ base year electricity capacity is $Q_{p}^{k}$ of voltage class $k$, the electricity quantity growth rate of user $p$ is $r_{p}$ every year.

$Q_{t, p}^{k}=Q_{p}^{k}\left(1+r_{p}\right)^{(t-1)}$

Where, $Q_{t, p}^{k}$ is user $p$ ' power consumption of voltage class $k$ in the $t$ year.

Each voltage classes load demand when system peak load is:

$D_{t}^{k}=\sum_{p=1}^{P}\left(Q_{t, p}^{k} \eta_{C F p}^{k} / \eta_{L F p}^{k}\right) / 8760$

Where, $D_{t}^{k}$ is peak load demand of voltage class $k$ in the $t$ year; $\eta_{L F p}^{k}$ is user $p$ 'load rate of voltage class; $\eta_{C F p}^{k}$ is user $p$ 'simultaneity factor of voltage class $k$.

Simultaneity factor is the ratio between system highest load and the sum of maximum loads each user. There is a relationship between users' simultaneity factor and the load ratio. Normally, the load ratio is higher, simultaneity factor is higher; otherwise, the load ratio is lower, simultaneity factor is lower. We can get the relationship between the load ratio and simultaneity factor though investigating and counting.

\subsection{Transmission and Distribution Loss Calculation Model}

After getting the highest load demand of the maximum load day in view of each voltage class of simultaneity factor, we need calculate electric power transfer relationship of each voltage class at peak load period year after year. Firstly, we need confirm line loss rate and variable loss rate of each voltage class at peak load period. The article carry out calculating based on the benchmark year.

According to transmission line, converting substation' physical properties, we can calculate and get the proportional relationship between copper losses of line and converting substation and iron losses.

$\left\{\begin{array}{l}\eta_{L}^{k /(k+1)}=\eta_{\text {LossL }}^{k} / \eta_{\text {LossL }}^{k+1} \\ \eta_{T}^{k /(k+1)}=\eta_{\text {Loss } T}^{k} / \eta_{\text {Loss } T}^{k+1}\end{array}\right.$

Where, $\eta_{\text {LossL }}^{k}$ is the line loss rate of voltage class $k$; $\eta_{\text {Loss } T}^{k}$ is the variable loss rate which voltage class $k$ supply power to lower voltage class; $\eta_{\text {LossL }}^{k+1}$ and $\eta_{\text {Loss } T}^{k+1}$ is line loss ratio and variable loss rate of adjacent voltage class respectively.

Assuming voltage class $k^{\prime}$ power supply load is $S^{k}$, including power plants' power supply output of the voltage in the area and the power supply output of the higher voltage class; the users' load of voltage class $k$ is $D^{k} ; S^{k l}$ is the supply power load from voltage class $k$ to low voltage class $l, V^{k l}$ is the supply power load from high voltage class $k$ to voltage class 1 , electric power balanced model is given as:

$\left\{\begin{array}{l}S^{k}=\left(D^{k}+\sum_{l<k} S^{k l}\right) /\left(1-\eta_{\text {LossL }}^{k}\right) \\ S^{k l}=V^{k l} /\left(1-\eta_{\text {LossT }}^{k}\right), l<k \\ \delta_{k, l j}=V^{k l} / V^{k j}, l<k, j<k \\ \sum_{k=1}^{6} G^{k}=\sum_{k=1}^{6} D_{\text {LOSST }}^{k}+\sum_{k=1}^{6} D_{\text {LOSSL }}^{k}+\sum_{k=1}^{K} D^{k}\end{array}\right.$

Where, $\delta_{k, l j}$ is the supply power ratio from high voltage class $k$ to low voltage class 1 and $j ; D_{\text {LOSST }}^{k}$ and $D_{\text {LOSSL }}^{k}$ is substation losses load and line losses load of voltage class $k$ respectively; $G^{k}$ is power plant output of voltage class $k$, including purchasing power; $\delta_{i, j k}$ is the supply power ratio from high voltage class $i$ to low voltage class $j$ and $k ; G^{k}$ is supply power load; users' power load $D^{k}$ and $\delta_{k, l j}$ are known number, others are unknown number. 
We can get line loss rate and substation loss of each voltage class though adjusting $\eta_{L}^{k /(k+1)}$ and $\eta_{T}^{k /(k+1)}, k=1,2, \cdots, 5$ and iterative computation which making each voltage class achieve to balance between supplying power and consumption power.

\subsection{Each Voltage Class Incremental Load Calculation}

Beginning from the lowest voltage class, according to each voltage class' supply power relationship, we can calculate each voltage class' the highest supply power load of system peak load period to high voltage class.

For the lowest voltage class $380 / 220 \mathrm{~V}$, the supply power load of system peak load in $t$-th year is:

$$
\left\{\begin{array}{l}
S_{t}^{6}=P_{D T t}^{6} /\left(1-\eta_{\text {LossL }}^{6}\right) \\
P_{D T t}^{6}=D_{t}^{6}
\end{array}\right.
$$

Where, $P_{D T t}^{6}$ is the total peak load demand of voltage class $380 / 220 \mathrm{~V} ; D_{t}^{6}$ is the highest load demand of voltage class $380 / 220 \mathrm{~V} ; \eta_{\text {LossL }}^{6}$ is peak load line loss rate of voltage class $380 / 220 \mathrm{~V}$ in the highest load of system.

For higher voltage class, the next class supply power load must be considered when calculating the highest supply power load of the maximum load day. The highest demand power load of the voltage class is the sum of the highest supply power load of the next class and the highest load demand of the class. Assuming there is the power plant accesses to the next voltage class, deducting supply power load of the next class power plants in the highest load of system when calculating the highest supply power load. If the highest load demand of voltage class $k$ in the $t$-th year is $D_{l}^{k}$, the total peak load demand of voltage class $k$ in the $t$-th year is:

$$
P_{D T t}^{K}=D_{l}^{k}+\sum_{l<k}\left[V^{k l} /\left(1-\eta_{\text {Loss } T}^{k}\right)\right]
$$

Where, $P_{D T t}^{K}$ is the total peak load demand, including the load demand of the class and the supply power load demand to the next class.

The highest supply power load of voltage class $k$ in the $t$ th year is:

$S_{t}^{k}=P_{D T t}^{k} /\left(1-\eta_{\text {LossL }}^{k}\right)$

Calculating from the lowest voltage class to high voltage class step by step, we can solve the total peak load demand and the highest supply power load of the biggest load day of each voltage class.

The difference between the next year and the same year' the highest supply power loads of each voltage class, which is the highest supply power load incremental of each voltage class in the year. Therefore, the highest supply power load incremental of voltage class $k$ in the $t$-th year is:
$\Delta S_{t}^{k}=S_{t+1}^{k}-S_{t}^{k}$

The total load demand incremental is:

$\Delta P_{D T t}^{k}=P_{D T t+1}^{k}-P_{D T t}^{k}$

\section{LONG-TERM MARGINAL COST CALCULATING AND ALLOCATION MODEL}

\subsection{Average Incremental Cost Calculating Model}

Firstly, we need forecast the planning period line and power transformation' investment quantity of each voltage class each year, and carry out discounting according to a certain discounted rate:

$\eta_{N P V}\left(I_{L}^{k}\right)=\sum_{t=1}^{n} \frac{I_{t, L}^{k}}{(1+i)^{n}}$

$\eta_{N P V}\left(I_{T}^{k}\right)=\sum_{t=1}^{n} \frac{I_{t, T}^{k}}{(1+i)^{n}}$

Where, $I_{t, L}^{k}$ and $I_{t, T}^{k}$ is line investment quantity and power transformation investment quantity of voltage class $k$ in $t$-th year respectively; $i$ is discounted rate.

Long-term average incremental cost calculating formula is:

$$
\begin{aligned}
& S_{A I C L}^{k}=\eta_{N P V}\left(I_{T}^{k}\right) / \eta_{N P V}\left(\Delta S^{k}\right) \\
& S_{A I C T}^{k}=\eta_{N P V}\left(I_{T}^{k}\right) / \eta_{N P V}\left(\Delta P_{D T}^{k}\right)
\end{aligned}
$$

Where, $S_{A I C L}^{k}$ and $S_{A I C T}^{k}$ is line and power transformation long-term average incremental cost of voltage class $k$ respectively.

Finally, according to years investment recovery coefficient and considering operation and maintenance cost, calculating the planning period line and power transformation annuity of each voltage class in each period. Line average incremental cost annuity of voltage class $k$ calculating formula is:

$$
A_{L}^{k}=S_{A I C L}^{k}(A / P, i, n)+C=S_{A I C L}^{k} \frac{i(1+i)^{n}}{(1+i)^{n}-1}+S_{A C L L}^{k} \beta_{c}
$$

Where, $C$ are operation and maintenance cost each year; $\beta_{c}$ is operation and maintenance cost.

In like manner, we can get power transformation average incremental cost annuity of voltage class $k$, the formula is given as:

$$
A_{L}^{k}=S_{A I C L}^{k} S_{A I C L}^{k} \frac{i(1+i)^{n}}{(1+i)^{n}-1}+S_{A I C L}^{k} \beta_{c}
$$




\subsection{Long-term Marginal Cost' Allocation Methods and Models between Each Voltage Classes}

After calculating planning period each voltage class annuity in each stage, we allocate above-mentioned cost between each voltage classes. Using peak responsibility allocation methods, according to peak load demand and power transmission and power receiving relationship of each voltage class, we will annuity of each link allocate to each voltage class.

Assuming $500 \mathrm{kV}$ is the highest voltage class of provincial power grid, it only undertakes transmissions line incremental cost of the class. The calculating formula is given as:

$S_{A T}^{l}=A^{l}=A_{L}^{l} \eta_{N P V}\left(\Delta S^{l}\right) / \eta_{N P V}\left(\Delta \eta_{D T}^{l}\right)$

Where, $S_{A T}^{l}$ is the total long-term marginal cost annuity which voltage class $k$ undertake.

The other each voltage class not only undertakes the class' transmission and distribution capacity cost, but also undertakes transmission and distribution capacity cost of the last voltage class according to inputting incremental power flow from the last class. There is some low voltage classes' power from many high voltage classes, for example, normally $35 \mathrm{kV}$ voltage class' power from $110 \mathrm{kV}$ and $220 \mathrm{kV}$ voltage class, so it should undertake two high voltage class' expenses which are allocated according to incremental power flow ratio. Voltage class $k(k \neq 1)$ should undertake high voltage class expenses calculating formula is expressed as:

$A_{H}^{k}=\sum_{h \gtrless k}\left[\left(S_{A T}^{h} \eta_{N P V}\left(\Delta S^{h}\right)\right)\left(\eta_{N P V}\left(\Delta V^{h k} / / \eta_{N P V}\left(\Delta P_{D T}^{h}\right)\right)\right] / \eta_{N P V}\left(\Delta P_{D T}^{k}\right)\right.$

Where, $A_{H}^{k}$ is voltage class $k$ should undertake the last class transmission and distribution power marginal cost annuity; $\Delta V^{h k}$ is the supply power incremental load from high voltage class $h$ to voltage class $k$.

Because a voltage class supplies power to the lower voltage class though reduction voltage, so transformer substation incremental expense should share to the lower voltage class which is related to the voltage class. This is deemed to the lower voltage class' expense, the expense calculation formula is given as:

$A^{k}=\left[\sum A_{T}^{h} \eta_{N P V}\left(\Delta V^{h k}\right)+A_{L}^{k} \eta_{N P V}\left(\Delta S^{k}\right)\right] / \eta_{N P V}\left(\Delta P_{D T}^{k}\right)$ is:

The total expense which is undertaken to voltage class $k$

$S_{A T}^{k}=A_{H}^{k}+A^{k}$

Finally, it will calculate each stage transmission and distribution price of different voltage class of planning period. After calculating transmission and distribution annuity of each voltage class, according to each stage load hours of different voltage class, it will turn transmission and distribution annuity into transmission and distribution price which is electricity price form.

\section{THE MEASURE OF POWER GRID LONG-TERM MARGINAL COST OF $A$ AREA}

\subsection{The Electric Power Development Planning of $A$ Area}

According to $A$ area electric power company development planning, forecasting $A$ area grid electricity demand in the planning period, and each type user of electricity consumption of $A$ area grid each voltage class and the ratio of each voltage class electricity consumption. Through analyzing each type user of electricity trend in the future, we calculate each year each type user of each voltage class' electricity consumption in the planning period. According to $A$ area electric power demand situation, the technical and economic indexes of power grid source which is existing and will be built, we optimize $A$ area future power extension situation through adopting the planning method that is based on the minimum expense, and get power planning program and electric power balanced situation. According to $A$ area electric power company development planning, we can get $A$ area each year all classes of power grid constructing program and the static investment year by year in the computing period.

\subsection{The Measure of Each Voltage Class of Incremental Load}

According to the statistic data in the $A$ area, we can get each voltage class each type user of load rate, simultaneity factor, as shown in the Table (1). The voltage class is higher, load rate is higher. For different industry, great industry users' load rate is the highest, lighting users' load rate is the lowest; the simultaneity factor of lighting users and great industry users is relatively high, and the simultaneity factor of agricultural users is relatively low.

According to each voltage class each type user of forecasting electric quantity in the planning period, and each type user of load rate and simultaneity factor, we can calculate and get each voltage class supply power load incremental year by year and the discounted value of incremental load, the results are shown in Table (2).

According incremental load and each voltage class electricity generation output situation, we calculate each voltage class incremental load from low voltage class step by step, and the results are shown in Table (3).

\subsection{The Measure of Each Voltage Class Long-term In- cremental Cost}

The paper offers the measure steps of each voltage class long-term incremental cost is given as:

Firstly, the article solved each voltage class each year highest load incremental in the period, and calculated each voltage class net present value of the total load incremental. 
Table 1. Occurrence time of maximum load, load rate, simultaneity factor of each type user at each voltage level.

\begin{tabular}{|c|c|c|c|c|}
\hline Voltage Level & User Class & Rush Time & Load Rate & Simultaneity Factor \\
\hline \multirow{5}{*}{$380 / 220 \mathrm{~V}$} & Non and General Industrial Users & 11:00 & 64 & 86 \\
\hline & Agricultural Users & 20:00 & 52 & 66 \\
\hline & Business Users & 18:00 & 51 & 80 \\
\hline & Residential Users & 20:00 & 42 & 80 \\
\hline & Lighting Users & 20:00 & 34 & 96 \\
\hline \multirow{7}{*}{$10 \mathrm{kV}$} & Great Industrial Users & $11: 00$ & 82 & 92 \\
\hline & Non and General Industrial Users & 11:00 & 67 & 87 \\
\hline & Agricultural Users & 20:00 & 55 & 68 \\
\hline & Business Users & 18:00 & 53 & 85 \\
\hline & Residential Users & 20:00 & 44 & 85 \\
\hline & Lighting Users & 20:00 & 34 & 98 \\
\hline & Wholesale Users & 18:00 & 51 & 7 \\
\hline \multirow{5}{*}{$35 \mathrm{kV}$} & Great Industrial Users & 11:00 & 86 & 94 \\
\hline & Non and General Industrial Users & 11:00 & 70 & 88 \\
\hline & Agricultural Users & 20:00 & 57 & 70 \\
\hline & Business Users & 18:00 & 56 & 90 \\
\hline & Wholesale Users & 20:00 & 62 & 80 \\
\hline \multirow{3}{*}{$110 \mathrm{kV}$} & Great Industrial Users & 10:00 & 86 & 94 \\
\hline & Non and General Industrial Users & $10: 00$ & 70 & 88 \\
\hline & Wholesale Users & 10:00 & 78 & 90 \\
\hline $220 \mathrm{kV}$ & Send to Other Provinces & $10: 00$ & 91 & 90 \\
\hline
\end{tabular}

Table 2. Incremental load of each voltage level year after year and discounted present value of total incremental load.

\begin{tabular}{|c|c|c|c|c|c|c|}
\hline \multirow{2}{*}{ Time } & \multicolumn{5}{|c|}{ Load/MW } \\
\cline { 2 - 7 } & $\mathbf{3 8 0 / 2 2 0 V}$ & $\mathbf{1 0 k V}$ & $\mathbf{3 5 k V}$ & $\mathbf{1 1 0 k V}$ & $\mathbf{2 2 0 k V}$ & $\mathbf{5 0 0 k V}$ \\
\hline \hline First Years & 9 & 38 & 46 & 89 & 54 & 27 \\
\hline Second Years & 11 & 49 & 60 & 115 & 134 & 14 \\
\hline Third Years & 13 & 61 & 76 & 145 & 184 & 0 \\
\hline Forth Years & 18 & 77 & 87 & 172 & 212 & 5 \\
\hline Fifth Years & 20 & 84 & 93 & 186 & 246 \\
\hline
\end{tabular}


Table 2. contd...

\begin{tabular}{|c|c|c|c|c|c|c|}
\hline \multirow{2}{*}{ Time } & \multicolumn{6}{|c|}{ Load/MW } \\
\hline & $380 / 220 \mathrm{~V}$ & $10 \mathrm{kV}$ & $35 \mathrm{kV}$ & $110 \mathrm{kV}$ & $220 \mathrm{kV}$ & $500 \mathrm{kV}$ \\
\hline Seventh Years & 24 & 97 & 105 & 212 & 264 & 193 \\
\hline Ninth Years & 29 & 113 & 112 & 235 & 285 & 9 \\
\hline Tenth Years & 32 & 126 & 118 & 255 & 330 & 771 \\
\hline Discounted Present Value of Total Incremental Load & 101 & 426 & 473 & 943 & 1134 & 870 \\
\hline
\end{tabular}

Table 3. Discounted value of incremental load of each voltage level.

\begin{tabular}{|c|c|c|c|c|c|c|}
\hline The Level Peak Load Demand Incremental/MW & 96 & 302 & 432 & 227 & 0 & 152 \\
\hline The Total Power Supply Load Incremental/MW & 101 & 426 & 473 & 943 & 1134 & 869 \\
\hline The Total Load Incremental/MW & 96 & 406 & 455 & 919 & 1098 & 848 \\
\hline Power Supply Incremental From 35kV/MW & - & 0 & 22 & 0 & 0 & 0 \\
\hline Power Supply Incremental From 110kV/MW & 0 & 404 & 281 & 0 & 0 & 0 \\
\hline Power Supply Incremental From 220kV/MW & 0 & 0 & 192 & 898 & 0 & 0 \\
\hline The Level Peak Load Line Loss Rate/\% & 5.65 & 4.73 & 2.58 & 2.55 & 3.15 & 2.41 \\
\hline The Level Peak Load Variable Loss Rate/\% & 0.00 & 2.13 & 2.48 & 0.85 & 0.78 & 0.47 \\
\hline
\end{tabular}

Secondly, according to $<A$ area electric power development plan $>$ of $A$ area electric power company and each year $500 \mathrm{kV}$ and $220 \mathrm{kV}$ grid construction program and static investment net present value year by year of regional power grid in the period, the paper calculated each voltage class the annual investment and the total investment net present value in the future.

Finally, the article calculated each voltage class transmission and distribution average incremented cost. If electric transmission and transformation equipment life is $25 \mathrm{a}$, the discount rate is $12 \%$, the operation and maintenance cost is $2 \%$ of the assets, we can calculate each voltage class annuity. Each voltage class average incremental cost and annuity is shown in the Table (4).

\subsection{The Distribution Method of Long-term Marginal Cost Between Each Voltage Class}

According to the parameter of Table 3 and Table 4, the paper solved each voltage class long transmission and transformation marginal cost and annuity.

The total transmission and transformation capacity marginal cost and annuity of $500 \mathrm{kV}$ voltage class is $345 \mathrm{yu}-$ $\mathrm{an} /\left(\mathrm{kW}^{\circ} \mathrm{a}\right)$.

$35 \mathrm{kV}$ voltage class undertakes the long-term transmission and transformation marginal cost and annuity of $220 \mathrm{kV}$ and $110 \mathrm{kV}$ voltage class is $(594 * 193+1021 * 284) / 455=878$ yuan $/\left(\mathrm{kW}^{\circ} \mathrm{a}\right)$. 
Table 4. Average incremental cost and annuity of each voltage level.

\begin{tabular}{|c|c|c|c|}
\hline Voltage Level & Asset Types & Average Incremental Cost/(yuan/kW) & Annuity/(yuan/kWa) \\
\hline $380 / 220 \mathrm{~V}$ & Line Section & 854 & 126 \\
\hline $10 \mathrm{kV}$ & Line Section & 474 & 70 \\
\hline $35 \mathrm{kV}$ & Line Section & 732 & 108 \\
\hline \multirow{2}{*}{$110 \mathrm{kV}$} & Transformation Section & 556 & 82 \\
\hline & Line Section & 638 & 94 \\
\hline \multirow{2}{*}{$500 \mathrm{kV}$} & Transformation Section & 1753 & 259 \\
\hline & Line Section & 2280 & 336 \\
\hline
\end{tabular}

Table 5. Details of average incremental cost of each voltage level.

\begin{tabular}{|c|c|c|c|}
\hline Voltage Level & $\begin{array}{c}\text { Undertaking Higher Level } \\
\text { Expense/(yuan/kW'a) }\end{array}$ & $\begin{array}{c}\text { Undertaking the Level } \\
\text { Expense/(yuan/kW'a) }\end{array}$ & $\begin{array}{c}\text { Total Transmission } \\
\text { Cost/(yuan/kW'a) }\end{array}$ \\
\hline \hline $500 \mathrm{kV}$ & 0 & 345 & 345 \\
\hline $220 \mathrm{kV}$ & 218 & 376 & 594 \\
\hline $110 \mathrm{kV}$ & 586 & 436 & 1021 \\
\hline $35 \mathrm{kV}$ & 878 & 306 & 1184 \\
\hline $10 \mathrm{kV}$ & 1110 & 203 & 1313 \\
\hline $380 / 220 \mathrm{~V}$ & 1543 & 275 & 1819 \\
\hline
\end{tabular}

The level long-term transmission and transformation capacity marginal costs of $35 \mathrm{kV}$ voltage class include transformation and transmission. The long-term transmission and transformation marginal cost and annuity of $35 \mathrm{kV}$ voltage class is $(334 * 192+82 * 2811+108 * 473) / 455=306$ yuan $/(\mathrm{kW}$. a).

Therefore, $35 \mathrm{kV}$ voltage class undertakes the long-term transmission and transformation capacity marginal cost and annuity is $878+306=1184$ yuan $/\left(\mathrm{kW}^{\circ}\right.$ a) .

In like manner, we can get the long-term transmission and transformation capacity marginal cost and annuity of others voltage classes. The measure results are shown in Table (5). Due to low voltage class need undertake high voltage class expense, with the decline of voltage class, the undertaken an annual expense will gradually increase. Each voltage class long-term incremental annuity are shown in the Table (5), according to the calculating results translate into transmission price (the single electricity price or two-part tariff), or according to each type user' user characteristics, design user sale price together with the long-term generation marginal cost.

\section{CONCLUSION}

Marginal cost pricing method which is based on marginal cost is gotten according to the system actual power supply cost increase as a result of each type user power consumption increasing. It will reflect actual power supply cost of different power supply voltage, different load characteristic user, and it is advantage of eliminating cross-subsidization, making electricity price which each voltage class undertake more reasonable and fair. Through calculating and sharing long-term marginal cost, and getting each voltage class longterm marginal capacity cost share into each type user. It will form scientific, reasonable user electricity price with power supply quantity cost. 


\section{CONFLICT OF INTEREST}

The authors confirm that this article content has no conflicts of interest.

\section{ACKNOWLEDGEMENTS}

Declared none.

\section{REFERENCES}

[1] G. Wang, and S. Fu, "Allocation of transmission charges using load flow tracing method," Automation of Electric Power Systems, vol. 28, no.9pp. 25-27, 2004. (in Chinese).

[2] S. Fu, Z. Rui, and H. Wang, "Computation and allocation of transmission charges," Automation of Electric Power Systems, vol. 28, no. 3, pp. 5-9, 2004. (in Chinese).

[3] H. Liu, G. Mu, M. Liu, Y. Yu, and J. Cao, "Comparison of accounting theory-based methods for transmission payment calculation in electricpower market," Electric Power Automation Equipment, vol. 25, no.11, pp.11-14, 2005. (in Chinese).

[4] D. Shirmohammadi, P. R. Gribik, E. T. K. Law, and J. H. Malinowski, "Evaluation of transmission network capacity use for wheeling transactions," IEEE Trans on Power Systems, vol. 4, no.4, pp.1405-1413, 1989.
[5] H. H. Happ, "Cost of wheeling methodologies," IEEE Trans on Power Systems, vol. 9, no.1, pp.147-156, 1994.

[6] Q. Xia, and Z. Sun, "New transmission pricing method based on optimal supply-demand match and MW-mile," Automation of Electric Power Systems, vol. 29, no. 24, pp. 9-13, 2005. (in Chinese)

[7] Y. Dai, Y. Ni, F. Wen, and Z. Han, "Reactive power pricing basedon cost allocation through power flow tracing," Automation of Electric Power Systems, vol. 24, no.18, pp.13-17, 2000. (in Chinese)

[8] G. Duan, X. Wang, W. Bai, and Y. Han, "Monetary flows : monetarypaths method for electricity transmission pricing," Proceedings of the CSEE, vol. 23, no. 3, pp.48-53, 2003. (in Chinese).

[9] J. W. M. Lima, "Allocation of transmission fixed charges: anoverview," IEEE Trans on Power Systems, vol. 11, no. 3, pp. 1409$1418,1999$.

[10] E. L. Silva, S. E. C. Mesa, and M. Morozowski, "Transmission access pricingto wheeling transactions: a reliability based approach," IEEE Trans on Power Systems, vol. 13, no. 4, pp.1481$1486,1998$.

[11] G. Ma, and L, Wang, "A long term marginal cost method fortwopart electricity pricing of power plant," Power System Technology, vol. 26, no. 9, pp. 51-54, 2002. (in Chinese).

[12] B. Jia, X. Wang, and X. Wang, 'Types of electricity marginalpricing and its specialties," East China Electric Power, no. 8, pp. 1-3, 2000. (in Chinese).

[13] C. $\mathrm{Yu}$, "Long run marginal cost-based transmission pricing inmultiarea systems," Electric Power Science and Engineering, no.1, pp. $1-7,2004$.

(C) Yi-xin et al.; Licensee Bentham Open.

This is an open access article licensed under the terms of the (https://creativecommons.org/licenses/by/4.0/legalcode), which permits unrestricted, non-commercial use, distribution and reproduction in any medium, provided the work is properly cited. 